ESTUDIOS 



\section{1. \\ Derecho privado}



Revista de Derecho

de la Pontificia Universidad Católica de Valparaíso

XXXIV (Valparaíso, Chile, $1^{\text {er }}$ Semestre de 2010)

[pp. 39 - 73]

\title{
JURISPRUDENCIA POR DAÑOS EN ESTACIONAMIENTO DE VEHÍ́CULOS REGIDO POR LA "LEY DEL CONSUMIDOR"*
}

["Jurisprudence Based on the "Consumer Law" Regarding Damages in Parking Lots"]

\author{
Marcelo Barrientos Zamorano** \\ Pontificia Universidad Católica de Chile
}

\begin{abstract}
RESUMEN
Este trabajo versa sobre los problemas de responsabilidad civil que acarrea el estacionamiento de vehículos. Se analiza la naturaleza jurídica de este tipo de contrato, sus obligaciones de acuerdo a la ley 19.496 y la disciplina supletoria del Código Civil en la materia. El artículo dedica una parte especial a la indemnización de perjuicios que pudieran derivarse del incumplimiento de este contrato, para ello se estudian, entre otras materias, la prueba de los perjuicios, la diligencia debida del proveedor del estacionamiento, la responsabilidad en caso de hurtos, robos o daños en estacionamientos gratuitos o remunerados. En todos estos
\end{abstract}

\begin{abstract}
This study is related to civil liability issues that involve vehicle parking. The legal nature and obligations arising from this type of contract, according to law 19.496 and the complementary discipline of the Civil Code regarding this matter, is herein analyzed. Part of this paper is specially focused on compensation for damages that might arise from the non-fulfillment of this contract. Among other matters, we study the due diligence of the parking lot supplier, liability in case of petty theft, thefts or damages in free or paid parking lots. The different doctrinal points of view are set forth in all these topics, together with the pertinent
\end{abstract}

* Este artículo forma parte del Proyecto Límite 01/2009: "La valoración de los daños morales en la indemnización de perjuicios por incumplimiento contractual civil", en que el autor es investigador. Este concurso fue adjudicado por la Vicerrectoría Adjunta de Investigación y Doctorado de la Pontificia Universidad Católica de Chile.

** Doctor en Derecho por la Universidad de Salamanca, España; magíster en Derecho de la Empresa por la Pontificia Universidad Católica de Chile. Profesor de Derecho Civil de la Facultad de Derecho de la Pontificia Universidad Católica de Chile. Dirección postal: Facultad de Derecho, Pontificia Universidad Católica de Chile, Alameda Bernardo O’Higgins , Santiago, Chile. Correo electrónico: mhbz@uc.cl 
temas se exponen los diferentes puntos de vista doctrinarios, junto a la jurisprudencia relevante, tanto en el Derecho chileno como en el extranjero.

Palabras clave: Responsabilidad Civil - Daños - Estacionamientos - Ley del consumidor. legal practice, both in the Chilean as well as in the foreign Law.

Keywords: Civil Liability - Damages - Parking Lots - Consumer Law.

\section{INTRODUCCIÓN}

Cuando alguien estaciona un vehículo en cierta ciudad o fuera de ella, ello puede dar origen a infinidad de contratos innominados y de relaciones jurídicas totalmente diferentes, que dependen del lugar elegido. En casi todas las ciudades del país comienzan a proliferar día a día los lugares en que se cobra por estacionar, y los estacionamientos gratuitos son excepcionales. Todo parece indicar que cada vez serán mayores los costos económicos y las implicancias jurídicas que tendrá que asumir un automovilista para moverse por una ciudad grande o pequeña en su vehículo. Estacionar en cualquier sitio gratuitamente, según parece, será un privilegio en extinción ${ }^{1}$.

No es una misma figura la que permite llenar de contenido un contrato de estacionamiento de vehículos en el ámbito del Derecho ${ }^{2}$.

${ }^{1}$ Esta apreciación también se desprende de noticias de prensa nacional como la de El Mercurio del domingo 9 de agosto de 2009, cuerpo B 6, sección "Economía y Negocios Domingo", que describe la proliferación de estacionamientos como " $e l$ boom de inversión en el rubro", enfatizando que "la mayor alza está en las clínicas". Esto último no deja de ser preocupante porque nos preguntamos si puede haber otro lugar, como este, en el que estacionarse es casi siempre una necesidad que puede llegar a ser vital. Creemos que es de suponer que el costo del estacionamiento está incluido en el costo de la prestación médica, la que no es barata, y que será pagada en su atención profesional al servicio médico consultado al interior de la clínica. Pues bien, como aclara la nota de prensa "casi todas las clínicas encuestadas han ajustado al alza el precio de los estacionamientos comparado con 2006". En definitiva hoy en día, en cualquier lugar, "hasta \$1.400 por hora cuesta estacionarse en Santiago" y "una estadía de más de dos horas puede llegar a valer \$3.500".

${ }^{2}$ Entre otros, destacan por su análisis en el Derecho comparado: Herrada RoMERo, R. I., El contrato de garaje (Madrid, Edersa, 2000); Elguero y Merino, J. $\mathrm{M}^{\mathrm{a}}$, Garajes y aparcamientos: ¿arrendamiento o depósito? (Madrid, Tecnos, 1993), p. 11; Gallego Domínguez, Ignacio, Comentarios a la ley reguladora del contrato de aparcamiento de vehiculos, ley 40/2002, de 14 de noviembre. (Granada, Comares, 2003) pp. 29 ss.; Arroyo Aparicio, Alicia, El contrato de aparcamientos de vehículos (Madrid, Editorial Marcial Pons, 2008) pp. 30 ss.; Bercovitz Rodriguez-Cano, R., Aparcamientos, en Aranzadi Civil, 15 (noviembre de 2002); Álvarez Pérez, N., El contrato de aparcamiento de vehiculos. Notas a la Ley 40/2002, de 14 de noviembre, en 
El contrato puede ser gratuito, oneroso, temporal, real, permanente, en lugar determinado o indeterminado, con reserva de plaza previamente acordada o sin ella, mercantil, ajustado al Derecho del consumidor o civil, etcétera. El lugar en que se estaciona puede ser público o privado, en un "mall”, tienda o almacén, hotel, aeropuerto, playa, calle, clínica, hospital, entre otros.

Sin perjuicio de todas las figuras posibles, en este trabajo nos preocuparemos de una de las tantas combinaciones posibles de relación jurídica que en la práctica pueden darse: la los estacionamientos proveídos por empresas de bienes y servicios, sean ellos gratuitos o no.

Para este propósito, nos ocuparemos de cuatro aspectos que detectáramos en la doctrina y jurisprudencia de nuestros tribunales, que a nuestro juicio crean cierta perplejidad y han dado origen a dispares interpretaciones:

i) Naturaleza jurídica de un contrato de estacionamientos fuera de la "Ley del consumidor".

ii) El contrato de estacionamiento en la "Ley del consumidor".

iii) La indemnización de perjuicios por daños en contratos de estacionamiento.

iv) Jurisprudencia sobre daños reparables dentro de un estacionamiento regido por la "Ley del consumidor".

Hacia el final del artículo, y como es debido, daremos cuenta de nuestras conclusiones.

\section{NATURALEZA JURÍdicA DE UN CONTRATO DE ESTACIONAMIENTOS FUERA DE LA “LEY DEL CONSUMIDOR”}

\section{Contrato de estacionamiento celebrado entre particulares.}

El contrato de estacionamiento celebrado entre particulares es propiamente tal una acto que se celebra bajo las normas del contrato de arrendamiento del Código Civil. No rigen en este contrato la Ley No 18.101, que fija normas especiales sobre arrendamientos de predios urbanos, la que en su artículo segundo señala que: "Esta ley no será aplicable a los siguientes bienes raíces urbanos: 5 . Estacionamientos de automóviles y vehiculos”.

La renta para este tipo de contratos se fija por períodos fijos de días, meses o un tiempo relativamente amplio. Suele ser considerablemente

In Dret, 2 (2003), pp. 1-16.; CAZorla GonzÁlez, M. J., La responsabilidad derivada del contrato de aparcamiento, en Actualidad Civil, 6 (7 al 13 de febrero de 2000), pp. 193 ss. 
menor en su monto al que se obtendría si se estacionara el vehículo por igual período en un estacionamiento organizado como empresa.

$\mathrm{El}$ arrendatario de un lugar para estacionarse en los términos señalados es mero tenedor del lugar que ocupa, que usa y goza. La mayoría de las veces no hay documentación de respaldo ni contratos que prueben la existencia de estos arriendos.

La perfección de este contrato es claramente consensual. Si ingresa o no el vehículo al estacionamiento, no resulta ser relevante en el proceso de formación del contrato. El contrato de estacionamiento entre particulares primero debe ofertarse en función de la persona con quien se celebra el contrato y, luego, la plaza y su precio han de pagarse en función del local y no por el valor del automóvil que se guarda expresado en minutos, horas o fracciones de ellas.

En este contrato, y si él se celebra dentro de una comunidad de edificios o copropiedad inmobiliaria, no necesariamente hay determinación exacta de los vehículos que se estacionan; y puede estacionarse un día uno y otro día otro. Lo relevante es la persona a la que se arrendó el lugar para que se estacione. No es usual tampoco hacer entrega de las llaves del automóvil al arrendador, por lo que no se otorga necesariamente custodia del vehículo al dueño del local o plaza de estacionamiento.

Visto así, las obligaciones de conservación y custodia propias de este contrato sólo surgen si el vehículo queda al cuidado del arrendador ${ }^{3}$.

La obligación de vigilar y custodiar que va implícita en el contrato de estacionamiento celebrado entre privados resulta ser de menor intensidad, porque generalmente hay libre acceso al espacio que ocupa el vehículo, sin ningún control de acceso al recinto o en menor grado, y ello por dos razones: $i$ ) de la salida o entrada del lugar en donde se encuentra el vehículo, de ordinario se facilita clave o control de acceso al arrendatario, sobre todo si de edificios o copropiedades inmobiliaria se trata; y ii) cualquier

\footnotetext{
${ }^{3}$ En la práctica, los problemas que presentan este tipo de estacionamientos tienen que ver con la vida en comunidad de edificios o copropiedades inmobiliarias en general. No son pocos los edificios en que terceros ajenos a él han adquirido estacionamientos exclusivamente y no departamentos, lo que afecta la seguridad de la copropiedad inmobiliaria en su conjunto. Es común que se realicen arrendamientos de un lugar para estacionarse para abaratar los costos de gastos comunes del resto de los propietarios del edificio, incluso, se arriendan mientras las constructoras venden todas las unidades que les faltan enajenar en un edificio. Así parece ocurrir en la práctica de acuerdo a noticias de prensa nacional como la de El Mercurio del domingo veintitrés de agosto de 2009, en la sección "Clasificados Propiedades", página tres, que describe "Los riesgos de arrendarle a un extraño" en alusión al alquiler de estacionamientos en edificios residenciales.
} 
copropietario o a quien se haya autorizado por alguno de éstos, pueden ingresar al lugar sin mayor escrutinio ${ }^{4}$.

Con los problemas de seguridad que puede acarrear el arrendar a desconocidos un estacionamiento dentro de la comunidad de copropietarios, cabe preguntarse si ¿es posible prohibirle a un copropietario la posibilidad de arrendar a terceros ajenos al edificio o comunidad un estacionamiento de su propiedad?

Pareciera ser que no; pero la respuesta admite dos posibles interpretaciones.

La primera se refiere a que la Ley No 19.537 de copropiedad inmobiliaria no señala norma especial en la materia. Pareciera, en todo caso, que si el "Reglamento de copropiedad" se pronuncia en contra de estas prácticas por parte de los copropietarios, no puede llevarse a cabo el arriendo de un estacionamiento dentro de la copropiedad. Así por lo menos se desprende del artículo 21 de la citada ley, que entrega al Comité de administración la facultad de imponer multas que estuvieren contempladas en el "Reglamento de copropiedad" para quienes infrinjan las obligaciones que en él se señalan 5 .

El tema no es pacífico, pues estas decisiones del comité de administración pueden ser revocadas por la asamblea ordinaria de copropietarios de acuerdo a la ley ${ }^{6}$. Es más, cualquiera de los copropietarios que quiera

${ }^{4} \mathrm{Al}$ empresario que se dedica a prestar servicios, cuya reglamentación debiera seguirse por la ley del consumidor, y que incluye en su oferta para atraer clientes un "estacionamiento gratuito" como ocurre en varios centros comerciales del país, pero que desarrolla una actividad claramente comercial o empresarial, le interesa esta interpretación porque se limitaría a entregar la cosa o automóvil. Tendría que hacer las reparaciones necesarias para conservar la plaza de estacionamiento en estado de servir y mantener al arrendatario en el goce pacífico del arrendamiento por el tiempo que dure el contrato, sin funciones de vigilancia o custodia del vehículo. VAQUero PinTo, M. J., Los contratos de estacionamiento de vehiculos (algunas reflexiones a propósito de la sentencia del Tribunal Supremo de 22 de octubre de 1996, en Estudios sobre Consumo, 48 (1999), pp. 83-94.

${ }^{5}$ Artículo 21 de la Ley No 19.537: "El Comité de Administración podrá también dictar normas que faciliten el buen orden y administración del condominio, como asimismo imponer las multas que estuvieren contempladas en el reglamento de copropiedad, a quienes infrinjan las obligaciones de esta ley y del reglamento de copropiedad".

${ }^{6}$ Artículo 28 de la Ley No 19.537: "Los copropietarios de un condominio deberán acordar un reglamento de copropiedad con los siguientes objetos: a) Fijar con precisión sus derechos y obligaciones reciprocos; b) Imponerse las limitaciones que estimen convenientes", en relación con artículo 17 de la misma ley que señala: "Todo lo concerniente a la administración del condominio será resuelto por los copropietarios reunidos en asamblea [...]. Las sesiones ordinarias se celebrarán, a lo menos, una vez al año, oportunidad en la que la administración deberá dar cuenta documentada de su gestión correspondiente 
arrendar a un tercero extraño al edificio un estacionamiento pudiera recurrir de protección constitucional si se lo prohíben, pues tal prohibición de arrendar, a su juicio, puede suponer una clara limitación a su derecho de propiedad y libre disposición de los bienes que le pertenecen y que se encuentra consagrado en la Constitución. Como se ve pugnan dos intereses jurídicos contrapuestos.

Una interpretación distinta de la anterior puede llevar a pensar que la prohibición de arrendar impuesta a algún copropietario podría derivar de una norma contenida en el "Reglamento de copropiedad" solamente, pero en ningún caso del Comité de Administración, ya que la norma del artículo 21 de la Ley No 19.537 no es posible deducir dicha facultad. En efecto, el artículo 28 de la citada ley, atribuye a los copropietarios la facultad de acordar en el "Reglamento de copropiedad" las limitaciones que estimen convenientes, normas que son obligatorias para los copropietarios y para los ocupantes a cualquier título. De estimarse que dichas limitaciones son constitutivas de una prohibición de arrendar, ellas serían contrarias a derecho. En consecuencia, bajo este punto de vista, se podría pedir judicialmente la revisión y modificación del "Reglamento de copropiedad" que expresa esta gravísima limitación al dominio, de conformidad con lo que sobre el particular se establece en el artículo 31 de la Ley sobre copropiedad inmobiliaria. Nos parece que el medio más rápido y eficaz en tal sentido es el recurso de protección ${ }^{7}$.

\section{Contrato de estacionamiento en la vía pública y en un taller mecánico.}

Distinto del anterior es el estacionamiento de un vehículo en la vía pú-

a los últimos doce meses y en ellas podrá tratarse cualquier asunto relacionado con los intereses de los copropietarios y adoptarse los acuerdos correspondientes, salvo los que sean materia de sesiones extraordinarias". Entre esas materias están la: "1. Modificación del reglamento de copropiedad'. si es que este prohíbe a los copropietarios arrendar el estacionamiento a terceros extraños al edificio.

${ }^{7}$ El artículo 31 de la Ley No 19.537 señala: "Los copropietarios que se sientan afectados por disposiciones del reglamento de copropiedad del condominio, por estimar que ha sido dictado con infracción de normas de esta ley o de su reglamento, o que contiene disposiciones contradictorias o que no corresponden a la realidad de ese condominio o de manifiesta arbitrariedad en el trato a los distintos copropietarios, podrán demandar ante el tribunal que corresponda de acuerdo a los articulos 33 y 34 de esta ley, la supresión, modificación o reemplazo de las normas impugnadas. La acción se notificará al administrador del condominio que para estos efectos tendrá la calidad de representante legal de los restantes copropietarios, debiendo ponerla en conocimiento de cada uno de los copropietarios, dentro de los cinco días hábiles siguientes a dicha notificación, mediante comunicación escrita dirigida al domicilio registrado por éstos en la administración o a falta de éste, a la respectiva unidad. En todo caso, cualquier copropietario podrá hacerse parte en el juicio". 
blica o calle. Este es más bien un servicio que ofrecen las municipalidades, previo pago de una tasa, que se relaciona a los minutos, horas o fracción que se está en el estacionamiento. Esta actividad puede estar concesionada o no y en ella no aparecen definidas obligaciones de custodia o guarda del vehículo. Se entrega un ticket, es cierto, en parquímetros servidos por personas o máquinas automáticas, pero estas personas o artefactos no controlan sino el cumplimiento de horarios y el pago de las tasas correspondientes que van, por lo general, a beneficio municipal.

Si se deja un automóvil en un taller de reparaciones no cabe sino calificar de obligación accesoria al servicio de reparación del vehículo el de estacionamiento en el taller. En efecto, la función principal es la de reparar el vehículo, lo que claramente se circunscribe, a nuestro entender, a la figura del contrato de arrendamiento y, más propiamente, en los contratos para la confección de una obra material de los artículos 1996 y siguientes CC. ${ }^{8}$. Ahora bien, creemos que las normas anteriores sólo pueden tener un carácter supletorio de acuerdo a la propia Ley No 19.946 del consumidor y lo señalado en el artículo 1 No 6 . Este contrato se debe regir por los artículos 3, letras d) y e), 12 y 23 de la Ley No 19.496. Es más, en el caso de daños al vehículo producto de la reparación en el taller mecánico, especial atención merece el artículo 41 inciso segundo de la "Ley del consumidor", por cuanto de acuerdo a esta disposición en lo pertinente se señala: "En todo caso, el consumidor podrá reclamar del desperfecto o daño ocasionado por el servicio defectuoso dentro del plazo de treinta días hábiles, contado desde la fecha en que hubiere terminado la prestación del servicio o, en su caso, se hubiere entregado el bien reparado. Si el tribunal estimare procedente el reclamo, dispondrá se preste nuevamente el servicio sin costo para el consumidor o, en su defecto, la devolución de lo pagado por éste al proveedor. Sin perjuicio de lo anterior, quedará subsistente la acción del consumidor para obtener la reparación de los perjuicios sufridos. Para el ejercicio de los derechos a que se refiere el presente párrafo, deberá estarse a lo dispuesto en el inciso final del artículo 21 de esta ley".

Como puede apreciarse esta no es sino una materia que se rige por el párrafo $4^{\circ}$ de la Ley sobre protección de los derechos del consumidor, referida

${ }^{8}$ Artículo 1996: "Si el artífice suministra la materia para la confección de una obra material, el contrato es de venta; pero no se perfecciona sino por la aprobación del que ordenó la obra./ Por consiguiente, el peligro de la cosa no pertenece al que ordenó la obra sino desde su aprobación, salvo que se haya constituido en mora de declarar si la aprueba o no./ Si la materia es suministrada por la persona que encargó la obra, el contrato es de arrendamiento./ Si la materia principal es suministrada por el que ha ordenado la obra, poniendo el artifice lo demás, el contrato es de arrendamiento; en el caso contrario, de venta./ El arrendamiento de obra se sujeta a las reglas generales del contrato de arrendamiento, sin perjuicio de las especiales que siguen". 
a las "Normas especiales en materia de prestación de servicios".

\section{Estacionamiento en un hotel o motel.}

Heterogéneo a los antes desarrollados es el estacionamiento en un servicio hotelero, sin perjuicio de que pudiera estimarse que en tal caso concurriría una relación que pudiera enmarcarse dentro de las de protección al consumidor. No obstante, las normas del artículo 2241 ss. CC. nos dan reglas claras respecto de este tipo particular de contrato de estacionamiento, que al menos tienen un carácter supletorio?.

\section{Experiencia comparada.}

En los contratos de estacionamientos en legislaciones comparadas, y que se rigen por el Código Civil en su caso, estamos frente una responsabilidad que puede estimarse ex recepto o agravada. Esto porque es un supuesto de responsabilidad ex lege, en consecuencia lo que se pretende es obligar a responder por la sustracción y los daños que sufran los bienes, y los automóviles entre ellos, de los clientes hospedados en un hotel.

${ }^{9}$ En este sentido, el artículo 2241 CC. nos señala que los efectos del que aloja en una posada introduciéndolos en ella, entregándolos al posadero o a sus dependientes, se miran como depositados bajo la custodia del posadero. Este depósito se asemeja al necesario y se le aplican los artículos 2237 ss. CC. Así, de acuerdo con el artículo 2242 CC.: "El posadero es responsable de todo daño que se cause a dichos efectos por culpa suya o de sus dependientes, o de los extraños que visitan la posada, y hasta de los hurtos y robos; pero no de fuerza mayor o caso fortuito, salvo que se le pueda imputar a culpa o dolo". Según el artículo 2243 CC., el posadero es además obligado a la seguridad de los efectos que el alojado conserva alrededor de sí. Bajo este respecto es responsable del daño causado o del hurto o robo cometido por los sirvientes de la posada, o por personas extrañas que no sean familiares o visitantes del alojado. Incluso el Código Civil regula el caso en que el alojado se queje de daño, hurto o robo, ya que deberá probar el número, calidad y valor de los efectos desaparecidos. Aparece facultado el juez para rechazar la prueba testimonial ofrecida por el demandante, cuando éste no le inspire confianza o las circunstancias le parezcan sospechosas, de acuerdo al artículo 2244 CC. Importante, por su eventual aplicación en el ámbito de la ley del consumidor, resulta la norma del artículo 2245 CC., pues si quien se hospeda en el hotel trajere consigo efectos de gran valor, de los que no entran ordinariamente en el equipaje de personas de su clase, deberá hacerlo saber al dueño del hotel, y aun mostrárselos si lo exigiere, para que se emplee especial cuidado en su custodia; y de no hacerlo así, podrá el juez desechar en esta parte la demanda. El propio artículo 2246 CC. señala qué ocurre si el deterioro de las cosas dejadas fuere, de algún modo, imputable a negligencia del alojado, en tal caso será absuelto el hostelero. Lo mismo ocurre si se ha convenido exonerarle de cualquier responsabilidad de acuerdo al artículo 2247CC. Cierran estas reglas la norma en que se hace extensiva esta reglamentación a los administradores de fondas, cafés, casas de billar o de baños, y otros establecimientos semejantes. 
En la jurisprudencia de otros países siempre ha respondido el empresario hotelero por estos daños. Como se puede apreciar en el contrato de depósito la guarda y custodia son esenciales y por extensión especialmente en el que se celebra con hoteleros, moteles u hostales. En Europa existe un Convenio del Consejo de Europa de 17 de diciembre de 1962, ratificado por Francia, pero no por España, que consagra los deberes de vigilancia y custodia como inherentes a esta actividad empresarial ${ }^{10}$.

Ante la gran cantidad de diferentes figuras jurídicas posibles analizadas hasta este punto, el Derecho comparado aporta algún tipo de síntesis o visión ecléctica.

De esta manera, en el Derecho y doctrina franceses se distingue entre el depósito y un contrato de "gardiennagge" para los automóviles, que no tiene obligaciones de guardia y custodia, sino más bien una obligación disminuida de vigilancia ${ }^{11}$.

En Italia, en cambio, prefieren decantarse por el contrato de depósito en términos similares al chileno, ya expuesto, tomando este contrato una reglamentación similar a la de nuestro Código Civil para el depósito irregular ${ }^{12}$.

Por la naturaleza de las prestaciones estamos ante un contrato, el de estacionamiento entre particulares que se asemeja al depósito civil, pero retribuido, ya que se reciben vehículos en un establecimiento donde, además, se les guarda y se ejerce sobre los automóviles un control directo.

\section{El CONTRATO DE ESTACiONAMIENTO EN LA "Ley DEL CONSUMidor"}

1. Los lugares de estacionamiento que se rigen por la "Ley del consumidor" están permanentemente destinados y abiertos al público, en horarios prefijados continuos o discontinuos y en ellos a veces, incluso, se puede llegar a disponer del automóvil por parte de los dependientes del negocio. Pueden estos guardadores o dependientes señalar dónde estacionar un vehículo o hacia dónde mover los automóviles que ya se encuentran estacionados en el interior del establecimiento por razones de mejor organización interna o espacio.

${ }^{10}$ Para un análisis reciente: Represa Polo, P., Responsabilidad de los establecimientos hoteleros por los efectos introducidos por sus clientes (Madrid, Editoriales de Derecho Reunidas, 2004); también en DíEz Soto, C. M., El depósito profesional (Barcelona, Bosch, 1995), p. 146.

${ }^{11}$ Huet, J., Traité de Droit Civil (sous la direction de Jacques Ghestin), Les principaux contrats spéciaux (Paris, L.D.G.J., 1996), pp, 1409 ss.

${ }^{12}$ Artículo 1839 CC.Ital.: "Cassette di sicurezza. Nel servicio delle cassette di sicurez$z a$, la banca risponde verso l'utente per l'idoneità e la custodia dei locali e per l'integrità della cassetta, salvo il caso fortuito". 
En nuestra opinión el contrato de estacionamiento de este tipo reúne características propias. No se puede predicar la misma figura jurídica para el caso de quien se estaciona en una playa o sitio de estacionamientos abierto al público por unas horas o fracciones de ellas, como asimismo, en el resto de los casos caracterizados anteriormente.

Así, en estos contratos de estacionamiento bajo la "Ley del consumidor" se asegura un uso determinado y temporal de una plaza a cambio de un precio, propio de un arrendamiento, y también se garantizan obligaciones de guarda y restitución, inherentes al depósito, agregándose por la propia "Ley del consumidor" la obligación de seguridad. El resultado de esta mezcla de contratos es la de un bien mueble que se deposita en un espacio ajeno, cuyo uso es cedido de manera temporal, obligándose la parte que deposita el bien mueble al pago de una renta (sin el cual no se puede retirar el vehículo) y la que la recibe a la cesión de uso temporal de un espacio de terreno para que se estacione el vehículo, en carácter exclusivo, con obligación de seguridad, vigilancia y custodia durante la vigencia del contrato.

Nada obsta a que haya otro tipo de prestaciones que puedan darse en carácter accesorio como lavado del vehículo, limpieza interna, encerado, grabado de puertas u otros servicios, como de ordinario ocurre.

A estos elementos, propios del contrato de estacionamiento, cabría agregar el de la legítima expectativa del usuario de recobrar su automóvil tal y cual lo dejó al estacionarlo. Estimamos que ello se traduce en una verdadera obligación de seguridad que aparece como esencial al contrato mismo de estacionamiento regido por la "Ley del consumidor". Lo anterior, incluso si consideramos que esta relación contractual es innominada, como ocurre en nuestro país.

2. Es este un típico caso de contratación en masa, en el que la autonomía de la voluntad tiene muy poco que decir ${ }^{13}$.

Este es un contrato extremadamente común y extendido en el que el oferente indica precios, horarios y normas de uso mediante carteles

${ }^{13}$ Gómez Calle, E., Los deberes precontractuales de información, en La Ley (1994), pp. 12: "Ese principio de individualismo impera en la época de la codificación decimonónica [...] desde este punto de vista, la información en la etapa precontractual había de considerarse (en la misma línea que en Roma) como una tarea propia de cada uno de los (futuros y eventuales) contratantes, únicos tutores de sus propios intereses, que se encuentran, además, en contraposición, a los del otro”. Para una lúcida exposición de estas ideas en relación al ordenamiento jurídico chileno, véase: TAPIA RODRÍGUEZ, M., Código Civil, 1855-2005, evolución y perspectivas (Santiago, Editorial Jurídica de Chile, 2005), pp. 210 ss.; y Tapia RodríGuez, M. - Valdivia, J. M., Contrato por adhesión. Ley $N^{o} 19.496$ ' (Santiago, Editorial Jurídica de Chile, 2002) pp.15 ss. 
al público ${ }^{14}$. Reúne, por lo tanto, todas las características propias de un contrato de adhesión, auténtica modalidad o sistema de contratación, en el que por consiguiente entran en juego todas las normas de protección del consumidor al ser una exigencia del sistema jurídico y su tráfico.

Quien es dueño de un estacionamiento de vehículos sugiere al público la celebración de infinidad de contratos diarios de este tipo y otros accesorios. Se aplica este régimen sea el oferente persona natural o jurídica ${ }^{15}$.

La duración de este contrato es indefinida y puede tener diferentes posibilidades en cuanto a su duración, por ejemplo: horas, días, semanas o meses. Es posible, sólo excepcionalmente, pactar prórrogas y ello independientemente que el vehículo se encuentre o no en el estacionamiento, lo que permite asegurar una plaza que puede ocuparse y desocuparse alternativamente.

De acuerdo a la ley, los empresarios o profesionales que pretendan que se contrate con ellos deben informar de modo cierto, eficaz, objetivo y suficiente sobre las características esenciales de los bienes, productos o servicios ${ }^{16}$. Es por lo anterior que la ley despliega una serie de prerrogativas de los consumidores, las que buscan la protección y seguridad de estos, y que es llevada a cabo mediante varios mecanismos que veremos a continuación.

El artículo 3 letra d) de la Ley No 19.496, señala que: "Son derechos $y$ deberes básicos del consumidor: d) La seguridad en el consumo de bienes o servicios, la protección de la salud y el medio ambiente y el deber de evitar los riesgos que puedan afectarles".

Todas estas características del contrato de estacionamiento, bajo la Ley del consumidor, permiten efectos virtuosos, tales como: celeridad en la

${ }^{14} \mathrm{Su}$ importancia hoy resulta alta, no en vano SERNAC informa al público sobre diferentes aspectos a considerar en este contrato de estacionamiento a través de su página web: http://www.sernac.cl/consejos/detalle.php?id=2000

${ }^{15}$ Ley No 19.456, artículo 2: "Proveedores: las personas naturales o jurídicas, de carácter público o privado, que habitualmente desarrollen actividades de producción, fabricación, importación, construcción, distribución o comercialización de bienes o de prestación de servicios a consumidores, por las que se cobre precio o tarifa.l No se considerará proveedores a las personas que posean un titulo profesional y ejerzan su actividad en forma independiente".

${ }^{16}$ Ley No 19.456, artículo 3: "Información básica comercial: los datos, instructivos, antecedentes o indicaciones que el proveedor debe suministrar obligatoriamente al público consumidor, en cumplimiento de una norma jurídica". En el inciso tercero se agrega: "En la venta de bienes y prestación de servicios, se considerará información comercial básica, además de lo que dispongan otras normas legales o reglamentarias, la identificación del bien o servicio que se ofrece al consumidor, asi como también los instructivos de uso y los términos de la garantía cuando procedan". 
contratación, costos operacionales más bajos y, sobre todo, riesgos menores para los empresarios del rubro, pero ¿y los consumidores están protegidos de la forma como el artículo 30, letra d) de la Ley No 19.496 señala?

Veamos. En relación a las características expuestas, resulta claro que la empresa de estacionamientos debe desplegar obligaciones de seguridad, custodia y guarda, las que ciertamente no son sino la obligación principal del contrato. Es a nuestro entender una obligación profesional y de medios $^{17}$. Nos parece que la diligencia exigible es la determinada por la "lex artis ad hoc" en estos casos. Estimamos que al deudor se le exige una conducta diligente para que alcance el acreedor la satisfacción de la prestación comprometida. No es así en las obligaciones de resultado en las que la diligencia no se mira, sino más bien precisamente el resultado obtenido. Esta idea sobre el tipo de obligación de medios, además, se refuerza por el hecho de que en estos contratos, y frente a su incumplimiento, resulta fundamental la organización o la culpa en la organización, como se verá más adelante está incluso ya reflejado en ciertos fallos nacionales ${ }^{18}$.

Dentro de los derechos y deberes de esta relación, y buscando proteger al consumidor, también se cuenta, en el artículo 3 b) de nuestra Ley No 19.496, la información veraz y oportuna en relación al precio, condiciones de contratación, la seguridad en el consumo de bienes, exposición sobre las características relevantes de los productos y la obligación de informarse sobre ellos ${ }^{19}$.

${ }^{17}$ Como indica Vidal Olivares, Álvaro, La protección del comprador. Régimen de la convención de Viena y su contraste con el Código Civil (Valparaíso, Ediciones Universitarias de Valparaíso, 2006). p. 175, quien sigue a DíEZ- PICAZO, L., Fundamentos de Derecho civil patrimonial. Introducción. Teoría general del contrato y las relaciones obligatorias (Madrid, Civitas, 1996), I-II, p. 236: "El incumplimiento en su sentido más amplio se confunde con la no realización de la prestación o, en otros términos, con cualquiera desviación del programa o plan ideal de prestación inicialmente acordado por las partes". En el mismo sentido, a fin de definir el alcance de la obligación y su objeto, se coloca el acento en el interés del acreedor y la prestación puede entenderse en dos sentidos: “a) como comportamiento efectivo del deudor que se confunde con el propio cumplimiento de la obligación; b) como plan o proyecto ideal contemplado inicialmente por las partes cuando nace la relación obligatoria y que se aspira que sea realidad en un momento posterior". De acuerdo: PIZARRO WiLSON, C., La culpa como elemento constitutivo del incumplimiento en las obligaciones de medio o de diligencia, en Revista de Derecho de la Pontificia Universidad Católica de Valparaíso, 30 (2008) 2, pp. 255-265.

${ }^{18}$ Corral Talciani, H., Lecciones de responsabilidad civil extracontractual (Santiago, Editorial Jurídica de Chile, 2003) p. 113.

${ }^{19}$ En Chile, Núñez Cabrera, D., Declaraciones y silencios en el ámbito precontractual, en Estudios de Derecho Civil (Santiago, LexisNexis, 2007), II, p. 340, considera que el silencio de un proveedor hacia un consumidor genera una eventual "respon- 
Se señala como un deber del proveedor no sólo suministrar la información básica comercial a la que hacemos referencia, sino que también y bajo la obligación general de seguridad propia de una relación de consumo, cumplir con el deber del proveedor de evitar los riesgos que puedan afectar al consumidor ${ }^{20}$.

En estos casos debieran expresarse en forma satisfactoria las condiciones del contrato que se celebrará en letreros a la vista del público. Su visibilidad ha de ser clara y con un lenguaje preciso, debiéndose expresar los precios, horarios, normas de uso y funcionamiento.

¿Cuáles son los mínimos requeridos en esta materia? Señala Morales Moreno que el deber de cada contratante de colaborar con el otro se condiciona en orden a evitar su error, cuestión que posee cierto carácter relativo, dependiendo de una serie de factores, tales como los conocimientos que el destinatario pueda fácilmente obtener según su situación y condición, y las posibilidades del declarante de evitar su propio yerro ${ }^{21}$.

¿Qué ocurre en la práctica? Si se ingresa en un estacionamiento pagado hoy se recibe un boleto de ingreso que no lleva, en casi el cien por ciento de los casos, cláusulas contractuales, si acaso aparecen pequeños letreros con avisos al interior donde se señalan las condiciones del estacionamiento.

El resguardo o boleto de ingreso, entonces, constituye la forma de consignar el día y la hora de entrada para la fijación del precio que se deberá pagar al salir del estacionamiento. Estimamos que no es un documento probatorio de la contraprestación del automovilista mientras el automóvil se encuentra en el estacionamiento, aunque en eso se convertirá cuando se pague al salir de él, si es que se recupera, porque no son pocas las veces en que una máquina, sin operador humano, priva al automovilista de este comprobante al salir del recinto. En consecuencia, si no se recupera el resguardo o boleto de ingreso, la boleta de pago gravada con el impuesto al valor agregado. será, en tal caso, el resguardo de haber pagado en el estacionamiento el servicio propio de este tipo de contrato.

En los contratos de estacionamiento nos parecen abusivas las exoneraciones de responsabilidad del dueño del estacionamiento. Ellas no han

sabilidad por el silencio". Reúne éste las características propias de un fraude que se constituye por dolo negativo o reticencia de acuerdo al artículo 20 de la "Ley del consumidor".

${ }^{20}$ Artículos 1, 3, 28, 30 y 50 de la ley, por nombrar algunos. Especial énfasis ha de tener la información precontractual sobre el contenido del contrato. Sobre ello: Barrientos Zamorano, M., Daños y deberes en las tratativas preliminares de un contrato (Santiago, LegalPublishing, 2008), pp. 73 ss.

${ }^{21}$ Morales Moreno, A. M., El error en los contratos (Madrid, Editorial Ceura, 1988) pp. 229-231. 
sido negociadas individualmente por los contratantes, entre otras razones por lo engorroso que ello sería. Sin embargo, el que sea difícil discutir cláusulas contractuales no ha de ser interpretado a favor del oferente del estacionamiento. No se puede señalar que estas cláusulas son válidas porque no cabe otra forma de hacerlas. Nada de eso, esta imposibilidad debe ser interpretada a favor del consumidor por el principio de protección implícito en la ley misma que señala que ante la desigualdad de las posiciones de los contratantes, las cláusulas deben interpretarse a favor del consumidor. Como señala un autor: "Al poder judicial, el derecho del consumo exige que tenga en cuenta la amplitud de las desigualdades que separan a los agentes -consumidores y profesionales- en el campo económico, y que mejore la posición de los consumidores recurriendo, principalmente, a los mecanismos jurídicos tradicionales del derecho de las obligaciones, del derecho de los contratos y de la responsabilidad, así como empleando nuevas interpretaciones e incluso nuevas normativas"22.

Es por lo anterior que consideramos que las cláusulas que excluyen o limitan los derechos legales del consumidor o usuario por incumplimiento total o parcial del que provee el estacionamiento no respetan la buena fe. Crean un importante desequilibrio de obligaciones, el que aparece desproporcionado e inicuo a los intereses de quien se haya en un plano inferior frente al proveedor del servicio de estacionamientos. Lo anterior ayudado por el hecho de que el empresario impone una renuncia o limitación de los derechos del consumidor, que en otros términos equivale a una cómoda cláusula en la que él, por sí y ante sí, expresa su eventual falta de cumplimiento de obligaciones propias y de lo que se espera sea su actuar durante el contrato.

A mayor abundamiento, estimamos que lo expuesto está señalado en nuestra "Ley del consumidor", letra g) del artículo 16, por cuanto en los contratos de adhesión, no producen ningún efecto las cláusulas que sean contrarias a la buena fe o produzcan un desequilibrio importante en las prestaciones que se deben recíprocamente proveedor y consumidor ${ }^{23}$.

${ }^{22}$ Bourgoignie, Thierry, Elementos para una teoría del Derecho de consumo (Vitoria, Departamento de Comercio, Consumo y Turismo de la Comunidad Vasca, 1994), p. 192.

${ }^{23}$ Artículo 16 de la Ley No 19.496: "No producirán efecto alguno en los contratos de adhesión las cláusulas o estipulaciones que:/ g) En contra de las exigencias de la buena $f e$, atendiendo para estos efectos a parámetros objetivos, que causen en perjuicio del consumidor, un desequilibrio importante en los derechos y obligaciones que para las partes se deriven del contrato. Para ello se atenderá a la finalidad del contrato y a las disposiciones especiales o generales que lo rigen. Se presumirá que dichas cláusulas se encuentran ajustadas a exigencias de la buena fe, si los contratos a que pertenecen han sido revisados $y$ autorizados por un órgano administrativo en ejecución de sus facultades legales". 
Es claro y pacífico en doctrina que la buena fe en esta materia ha de tomarse en sentido objetivo, el estándar de la buena fe objetiva es flexible y debe ir precisándose en forma casuística, según las circunstancias de cada caso. La buena fe en esta faz siempre tendrá importancia en el ámbito contractual, aquí estamos ante la confianza, la fidelidad, sinceridad, veracidad. Importa que en el contrato cada una de las partes se entregue a la conducta leal de la otra, ya que fía y confía que su contraparte no lo engañará o le evitará todo perjuicio. A esto llamamos actuar de buena fe. Esta es propiamente una conducta ${ }^{24}$.

La buena fe objetiva, en fin, es externa al sujeto y le impone una serie de deberes como hemos señalado, los que nos parecen que en este particular contrato serían fácilmente defraudados. Lo que se burlaría son las expectativas del consumidor si el proveedor del estacionamiento predispone cláusulas abusivas que claramente causan un notorio desequilibrio entre las prestaciones de ambas partes.

Una expresión de estas cláusulas no negociadas es el redondeo que se hace en la mayoría de los estacionamientos cuando el usuario se extralimita de media hora o fracción de ella a la hora completa ${ }^{25}$. Nos parece abusiva tal práctica en nuestro país por cuanto se trata de una cláusula no negociada individualmente por el consumidor y sobre la que éste no tiene control ${ }^{26}$.

${ }^{24}$ En el Código Civil hay muchos ejemplos en esta materia; así el artículo 1546: "Los contratos deben ejecutarse de buena fe, y por consiguiente obligan no sólo a lo que en ellos se expresa, sino a todas las cosas que emanan precisamente de la naturaleza de la obligación, o que por la ley o la costumbre pertenecen a ella". En el inciso $2^{\circ}$ del artículo 1576, se valida el pago hecho de buena fe a la persona que estaba entonces en posesión del crédito, aunque después aparezca que no le pertenecía. También en el pago, si éste no tiene validez, y ha consistido en la transferencia de la propiedad de una cosa fungible, se valida si el acreedor la ha consumido de buena fe. El artículo 2295 señala: "Si el que por error ha hecho un pago, prueba que no lo debia, tiene derecho para repetir lo pagado"; y el 2297 dice: "Se podrá repetir lo pagado aún por un error de derecho". La mala fe, en cambio, consiste en el conocimiento, mientras que la buena fe puede consistir en la mera ignorancia.

${ }^{25}$ En la ley española reguladora del contrato de aparcamiento, No 40/2002, de 14 de noviembre, este problema dio origen a una modificación legal por el carácter abusivo de esta fórmula en 2006. La ley propiamente tal, la No 44/2006, buscaba dar una mejora de protección a los consumidores. Tal es así que la citada reforma manda que para resolver el problema del "redondeo", el precio por ocupar el estacionamiento ha de estar determinado "en función del tiempo real de prestación del servicio".

${ }^{26}$ Tapia Rodríguez, M. - Valdivia, J. M., Contrato por adhesión. Ley No 19.496 (Santiago, Editorial Jurídica de Chile, 2002), pp. 109 ss.: "La doctrina de este siglo ha propendido a la exclusión de estas estipulaciones modificatorias de responsabilidad del contrato por adhesión, amparada en los principios de abuso de derecho y buena fe a que se ha hecho referencia, y que es la tendencia implícita en la Ley”. 
Agrava aún más esta precaria situación el hecho de que la prestación del consumidor, el pago del estacionamiento, es un elemento esencial del contrato. Así también se ha considerado en el Derecho comparado ${ }^{27}$.

Hay aquí una clara situación de desequilibrio de derechos y obligaciones que redunda en un perjuicio del consumidor, parte económicamente más débil de esta relación, ya que el empresario o predisponerte es el único beneficiado porque puede, cada vez que se desocupe un lugar de estacionamiento, volver a cobrar a otro consumidor por la misma fracción de hora que ya ha cobrado a quien anteriormente ocupaba la plaza correspondiente. Esta práctica creemos es, además, un enriquecimiento sin causa a costa del que ya ha abandonado la plaza de estacionamiento.

El costo por ocupar un estacionamiento pagado debiera ser cobrado como el que realmente representa el tiempo que ha estado estacionado el vehículo en el lugar, y por minuto, sin poderse redondear a unidades de tiempo que no se consumieron efectivamente.

De todo lo expuesto hasta aquí, es claro que la naturaleza jurídica de este contrato de estacionamiento se rige por las normas de la Ley No 19.496, que establece normas sobre protección de los derechos de los consumidores. Básicamente, lo dispuesto en el artículo $1 \mathrm{~N}^{\text {os }} 1$ y 2 , y 3, letras d) y e) de este cuerpo legislativo ${ }^{28}$. Este marco regulador permite que, al estar resguardada la relación de consumo entre proveedor y usuario de estacionamiento por la Ley No 19.496, tiene este último el derecho a seguridad en el consumo y, en consecuencia, a ser indemnizado en el caso de ocurrencia de daños en el estacionamiento que se oferta por el proveedor. Este concepto de seguridad englobaría tanto la seguridad de

\footnotetext{
${ }^{27}$ Carrasco Perera, A. - Medoza Losana, A. I., El carácter abusivo de la fórmula "hora o fracción" en los contratos de aparcamiento, en La Ley, 5588 (de 16 de julio de 2002).

${ }^{28}$ Artículo 1: "La presente ley tiene por objeto normar las relaciones entre proveedores y consumidores, establecer las infracciones en perjuicio del consumidor y señalar el procedimiento aplicable en estas materias./ Para los efectos de esta ley se entenderá por:/ 1.- Consumidores o usuarios: las personas naturales o jurídicas que, en virtud de cualquier acto jurídico oneroso, adquieren, utilizan, o disfrutan, como destinatarios finales, bienes o servicios./2.- Proveedores: las personas naturales o jurídicas, de carácter público o privado, que habitualmente desarrollen actividades de producción, fabricación, importación, construcción, distribución o comercialización de bienes o de prestación de servicios a consumidores, por las que se cobre precio o tarifa". El artículo 3 expresa: "Son derechos $y$ deberes básicos del consumidor:/ d) La seguridad en el consumo de bienes o servicios, la protección de la salud y el medio ambiente y el deber de evitar los riesgos que puedan afectarles./ e) El derecho a la reparación e indemnización adecuada y oportuna de todos los daños materiales y morales en caso de incumplimiento de cualquiera de las obligaciones contraídas por el proveedor, y el deber de accionar.
} 
no sufrir daños físicos ni materiales, como la seguridad en los productos. Se funda esta idea en los artículos 3, letras d) y e), ya señalados, y en los artículos 12 y 23 de la Ley No $19.496^{29}$.

La seguridad en el consumo ha de ser garantizada por el proveedor en términos tales que, de acuerdo a los fallos que pasaremos a analizar en el acápite siguiente, es posible demandar indemnización de perjuicios si los vehículos de los consumidores no son resguardados y custodiados por el proveedor. Supletoriamente entonces cabría acudir a las normas del depósito y del contrato de arrendamiento de los artículos 2211 ss. y 1915 ss. CC. respectivamente.

\section{LA INDEMNIZACIÓN DE PERJUICIOS POR DAÑOS EN CONTRATOS DE ESTACIONAMIENTO}

\section{Ley que ha de resolver los conflictos por incumplimiento.}

Todo parece indicar que mientras nos encontremos en medio de un contrato de estacionamiento, regido o no por la "Ley del consumidor", hemos de señalar que si alguna de las partes no cumple sus obligaciones tendremos que resolver los problemas que se presenten en el marco de la responsabilidad contractual. En este sentido, cabe expresar que la primera reacción será la de solicitar el cumplimiento forzado de las obligaciones o la resolución del contrato, en ambos casos, con indemnización de los perjuicios que siguieren al incumplimiento.

En este mismo orden de cosas, quien responda habrá de ser el dueño del estacionamiento, sus dependientes y, aplicando el principio de protección del consumidor, el que aparentemente sea dueño de él, como por ejemplo ocurre con los estacionamientos que por su color, disposición y letreros indican pertenecer al proveedor que se visita, como es el caso de los supermercados o grandes tiendas.

Es posible que en los hechos, por ejemplo, el estacionamiento no pertenezca a la empresa dueña de un supermercado que los ofrece como propios a sus clientes, pese a que exteriormente todo parece creado para invitar al consumidor a ocuparlos para consumir o no más tarde. Las más de las veces el lugar se identifica por señales de ser propio o estar disponible para

${ }^{29}$ Artículo 12: "Todo proveedor de bienes o servicios estará obligado a respetar los términos, condiciones y modalidades conforme a las cuales se hubiere ofrecido o convenido con el consumidor la entrega del bien o la prestación del servicio". Artículo 23: "Comete infracción a las disposiciones de la presente ley el proveedor que, en la venta de un bien $o$ en la prestación de un servicio, actuando con negligencia, causa menoscabo al consumidor debido a fallas o deficiencias en la calidad, cantidad, identidad, sustancia, procedencia, seguridad, peso o medida del respectivo bien o servicio". 
los clientes del supermercado en carácter de "exclusivo". El consumidor, en casos tan comunes como este, no puede saber que han sido arrendados estos lugares a otra empresa, más bien cree que son del oferente. Es por esto que la ley entiende que existe una presunción a favor del consumidor de que los estacionamientos así pintados, marcados o especificados son del proveedor que los oferta a sus clientes. Este criterio se va asentando en la jurisprudencia según veremos más adelante.

En definitiva, todo parece indicar que la doctrina y la propia jurisprudencia de manera incipiente, pero sostenida, cree que cuando nos estacionamos en un lugar determinado, ofertado al público por un proveedor de estacionamientos, no estamos ante contratos propiamente de depósito, y que la guarda y custodia son deberes contractuales propios de una relación de consumo más intensos que los del simple cuidado. Este es más bien un contrato innominado que comparte elementos del arrendamiento y el depósito, pero que sobre otras reglamentaciones se rige por los artículos 3 , letras d) y e), y en los artículos 12 y 23 de la Ley No 19.496 de protección al consumidor. Supletoriamente a nuestro entender, rigen las normas de los artículos 1556 ss. CC.

\section{Sobre el responsable civil y los seguros.}

Quien ha de responder frente al incumplimiento es la persona, natural o jurídica, que actualmente explota el estacionamiento en cualquier calidad que sea: dueño, arrendatario, subarrendatario, concesionario, usufructuario y cualquier otra denominación que reciba.

Cuestión diferente es si se ha contratado un seguro por responsabilidad civil, pues en tal caso ha de estarse a las normas propias de este tipo de contratos frente a estos daños. En cualquier caso, será siempre responsable de los daños el que haya contratado el seguro como proveedor del estacionamiento, más allá que sea la compañía de seguros la que cubra el riesgo y quien termine pagando los perjuicios ciertos, reales y efectivos, si proceden ellos de acuerdo a la póliza pactada.

Por los daños causados por terceros, y que deriven de una sustracción con fuerza en las cosas de carácter ilegítima en los vehículos, las aseguradoras no cubren el riesgo en general, si quien contrata los seguros es el estacionamiento mismo por los automóviles que alberga. Esto, por supuesto, sin perjuicio de lo que se encuentra cubierto por el seguro que el titular o dueño del vehículo tenía contratado. Aunque incluso en esta hipótesis, las aseguradoras tienden a cubrir los elementos fijos del vehículo y no los periféricos o especiales, a no ser que se hayan declarado al asumir el riesgo 
la compañía y se encuentren cubiertos por la póliza ${ }^{30}$.

En los seguros de responsabilidad civil rige el principio de la especialidad del riesgo, que se expresa básicamente en estos casos porque una empresa de seguros no ampara daños como consecuencia del actuar doloso de un asegurado. En otras palabras, es sólo asegurable en este tipo de riesgo la responsabilidad que proviene de la culpa o de meras conductas accidentales o en los que la voluntad del asegurado no juega un rol especial. Creemos que en esta materia, y relacionado con los seguros por daños en estacionamientos, debe primar una defensa de la unidad del vehículo que comprenderá razonablemente lo que cabe esperarse que tenga un vehículo en su interior mientras está estacionado.

\section{La prueba de los perjuicios.}

El problema más complejo en relación a este tipo de responsabilidad civil producto de daños en estacionamientos es, a nuestro juicio, el de la prueba del mismo. Así, si entendemos que existe una responsabilidad contractual ha de probarse que el estacionamiento realmente ha tenido lugar y que la obligación de seguridad no se ha cumplido de parte del proveedor $^{31}$.

Habitualmente se recurrirá, para probar la existencia del contrato de estacionamiento, al recibo de pago. Sin embargo, no es raro perder el usualmente pequeño comprobante de ingreso como ya se apuntó, que por cierto prueba que aun no se ha retirado el vehículo ni pagado el uso del estacionamiento. ¿Basta sólo el comprobante o boleta para probar que se ha estacionado en el lugar? Estimamos que no, pues ha de estamparse también un reclamo sobre el estado del vehículo, las pérdidas experimentadas por este o sus menoscabos durante la estancia en el estacionamiento. Debiera escribirse tal queja en el libro de reclamos del que debe disponerse en todo local que preste servicios de esta clase. En cualquier caso, estampar la denuncia correspondiente en Carabineros o pedir su presencia en el lugar inmediatamente no están de más en casos como el que nos ocupan.

De nuestra observación de la jurisprudencia, en estos casos se exige la prueba de la relación de causalidad, la que por cierto dependerá del criterio

${ }^{30}$ Ballesteros de los Ríos, M., El contrato de aparcamiento (Pamplona, Aranzadi, 2000), p.120.

${ }^{31}$ Herrada, Rafael Ignacio, El contrato de garaje y la ley 40/2002, reguladora del contrato de aparcamiento de vehículos, en Revista de Derecho Privado (enero-febrero de 2004), pp. 3-45, en España: “[...] se delimitará, en fin, la responsabilidad del garajista por los daños y perjuicios irrogados al usuario a consecuencia del incumplimiento imputable de la obligación de custodia. La práctica totalidad de las sentencias en la materia acogen este criterio". 
del tribunal. Nos referimos a una de las tantas teorías o criterios normativos que forman o prueban la relación de causalidad en juicio, tales como la razón suficiente, la causa adecuada, la mal llamada teoría de la equivalencia de las condiciones o la supresión hipotética de la causa (verdadero criterio normativo). En cualquier caso, el daño que sufre el acreedor ha de tener su origen en la falta de ejecución de la obligación de seguridad, vigilancia y custodia. Los menoscabos en tal caso, proceden del incumplimiento y se prueban o demuestran exponiendo al tribunal de que existe un nexo causal entre éste y los hechos que se prueban.

$¿$ Es posible concluir en este tema una cierta tendencia hacia la objetivación de la responsabilidad del dueño del estacionamiento?

Dos elementos nos llevan a concluir que sí. La inversión de la carga de la prueba y la necesidad de un grado de diligencia mayor que comprende en estos casos normas de seguridad. Este último criterio basado en una apreciación de la culpa en relación a expectativas legítimas que esperaba la víctima o consumidor al estacionarse.

Sobre la inversión de la carga de la prueba, es claro que de acuerdo al artículo 50 de la "Ley del consumidor" una infracción de los deberes del proveedor del servicio por acción u omisión y que determine daños y perjuicios, da lugar a responsabilidad. No la habrá si se logra acreditar que se han cumplido oportunamente las exigencias y requisitos reglamentarios establecidos en las leyes y, claramente a nuestro entender, la naturaleza del producto, servicio o actividad que en este caso está dado por la prestación del estacionamiento.

Recordemos que lo que sostenemos no es más que aplicación del artículo 1671 CC., en relación a la pérdida de la cosa que se debe, por el cual: "Siempre que la cosa perece en poder del deudor, se presume que ha sido por hecho o culpa suya". Si bien, la citada disposición pertenece a las obligaciones de dar, no es menos cierto que es de aplicación general en nuestro Derecho. Lo es por interpretación analógica o extensiva, y es dable concluir que tiene plena aplicación en esta clase de contratos.

Hay otro argumento supletorio que sustenta esta solución, ella es la del artículo que se relaciona con aquel contrato en que está basado el de estacionamiento, el de depósito, y específicamente la regla del artículo 2228 CC., por el que en lo pertinente se señala: "El depositario es obligado a la restitución de la misma cosa o cosas individuales que se le han confiado en depósito [...]".

Nos parece que en estos casos sólo puede quedar eximido el proveedor del estacionamiento si demuestra que empleó y agotó todas las medidas necesarias para evitar los daños causados, de ahí que sea una obligación de medios propia de la lex artis ad hoc. Constituye, en otras palabras, una 
obligación permanente vigilar y custodiar el vehículo y no es una quimera el pretender que sea devuelto en las condiciones en que fue estacionado, el proveedor debió proveer seguridad en el consumo de bienes o servicios y tiene en todo momento el deber de evitar los riesgos que pueden afectar a los consumidores, sean ellos finales o no. No cabría alegar falta de responsabilidad por parte del propietario del estacionamiento si fundamenta simplemente que los hechos se deben a acciones $\mathrm{u}$ omisiones de terceros pues, de acuerdo a nuestro artículo 1698 CC., deberá probarlo. Deberá probar, por ejemplo, si un automóvil que pertenece a un tercero choca a otro al interior del estacionamiento.

No es esta, como puede apreciarse, una responsabilidad objetiva por el resultado. Es una responsabilidad sujeta a prueba, y a prueba de los hechos que se alegan por parte de quien se pretende eximir de responsabilidad de acuerdo al artículo 1547 inciso $3^{\circ}$ CC. Ello porque entendemos que aquí hay responsabilidad derivada del incumplimiento de un contrato. Concurre entonces una presunción, cual es que los daños han tenido su origen en la culpa del dueño del estacionamiento. Esta idea se refuerza, aún más, por aplicación de las normas del consumidor y la presunción de culpa que ella hace del proveedor ante el incumplimiento de sus obligaciones, especialmente de seguridad, conforme a los artículos 3 letra d), 12 ss. y, en especial, 23 de la Ley No 19.496.

\section{La diligencia debida del proveedor de un estacionamiento.}

Sobre el nivel de diligencia exigido advertimos en la jurisprudencia, que más adelante comentaremos, una tendencia a elevar el grado de diligencia a uno especialmente cualificado ${ }^{32}$. Este nivel de diligencia para estos casos se caracteriza como aquel que se impone a los profesionales o empresarios en una actuación económica. Pareciera haber un alejamiento del buen padre de familia, con lo que el estándar sufre una leve modificación propia del Derecho del consumo. En efecto, quien explota un estacionamiento lo hace en el marco de una organización o explotación de carácter mercantil que ha de aumentar las medidas de diligencia ordinarias en la precaución de eventuales daños al pesar sobre él una obligación de seguridad. Esto no es cualquier índice o nivel de diligencia, sino aquel que se relaciona con el lugar, tiempo y las personas involucradas. Sin embargo, todavía se leen sentencias que en su gran mayoría sólo se remiten al estándar del buen padre de familia en nuestro país.

${ }^{32}$ Un criterio también visto en otras legislaciones comparadas como se explica en Díez Soto, C. M., El depósito profesional (Barcelona, Bosch, 1995), pp. 98 y 202-207. 
En este punto resulta atingente analizar el fallo del Segundo Juzgado de Policía Local de San Bernardo de 2006, el que en su considerando 28 expone: "[...] la causalidad entre los daños reclamados y la culpa o negligencia para los efectos de la Ley del Consumidor radica precisamente en el hecho de que ha sido la creación de una situación de riesgo para el consumidor por parte de su proveedor la que ha terminado produciéndole un daño que no es sino la concreción del riesgo no informado por el proveedor". Nos parece que en este caso el tribunal ha considerado pertinente asimilar al proveedor a una persona en posición de garante en su relación con el consumidor. Estima el tribunal que se habría creado una situación de riesgo para el consumidor ya que "[...] los perjuicios que se reclaman evidentemente son consecuencia del actuar de la demandada pues ha sido ella quien a sabiendas y con el exclusivo ánimo de beneficiarse ha creado una supuesta ventaja a sus clientes (facilitación de estacionamientos) que, sin embargo, representa para los mismos una situación de peligro, no informada"33.

En nuestro concepto, para entender estos supuestos ha de tenerse presente que se exige que exista una organización que habitualmente ofrece estacionamientos a sus clientes, sean ellos gratuitos o no. Este no es el caso de un particular que ofrece arrendar un espacio para estacionar rigiéndose por el Código Civil, como tampoco quien lo arrienda por cortos períodos de tiempo u ocasionalmente, bajo el mismo cuerpo de normas.

Tal y como señala Barros: "Por otro lado, referir la culpa al proceso o actividad empresarial tiene la ventaja de valorar el conjunto de la actividad del empresario, a efectos de comprobar si observa el estándar de debido cuidado. Por eso, la culpa organizacional, a diferencia de la derivada del hecho del dependiente, no requiere ser localizada en un agente específico, sino directamente en la función" ${ }^{4}$. Así en el fallo caratulado "Sandoval con Homecenter Sodimac", en su considerando 6o, se señala que: "[...] cabe apreciar que según aparece de los autos, la tienda ni siquiera contaba con servicio de cámaras de vigilancia operativas al interior del estacionamiento, por encontrarse, según señalaron sus empleados, en proceso de cambio el sistema de vigilancia electrónico, lo que constituye una inexcusable negligencia de parte de esta empresa". 35.

En otro fallo de la Corte de Apelaciones de Santiago también se ha conectado la culpa en la organización con las cláusulas que eximen de responsabilidad, nos referimos a aquellas unilaterales del proveedor del

33 “Astudillo con Supermercado El Líder” (2006).

${ }^{34}$ Barros Bourie, E., Tratado de responsabilidad extracontractual (Santiago, Editorial Jurídica de Chile, 2006), p. 196.

35 "Sandoval con Sodimac S.A." (2008), Corte de Apelaciones de Santiago, 30 de Julio de 2008. 
servicio: "La falta de cuidado de la concesionaria, constitutiva de la culpa leve, radica en la deficiencia del servicio prestado, explicada en este caso por la ausencia de elementos humanos o de infraestructura que permitan mantener bajo control las condiciones del recinto de estacionamiento -en el caso, la denunciada se negó a responder por la comisión de un ilícito del que fuera victima el consumidor alegando que se exhibia un aviso de eximición de responsabilidad por robos, hurtos o daños producidos en el interior de los estacionamientos subterráneos operados por ella, salvo en caso de comprobarse fehacientemente su responsabilidad o la de alguno de sus empleados en los hechos ocurridos-; sumando al caso que ésta no rindió ninguna probanza dirigida a demostrar la existencia de cajas de seguridad para sus clientes". La sentencia considera que ello es infracción al ya comentado artículo 23 inciso $1^{\circ}$ de la Ley No $19.496^{36}$.

Ha de tenerse otro elemento en cuenta en relación a la diligencia y es uno de carácter histórico. En los contratos de depósito, y este contrato de estacionamiento comparte esa naturaleza en parte, bajo Justiniano la culpa fue reducida en su influjo ante el incumplimiento otorgándose un mayor margen al riesgo que se crea en el incumplimiento ${ }^{37}$. Así, los casos de custodia en la responsabilidad civil son prácticamente objetivos al estar basadas en actos positivos del deudor o en violaciones de deberes contractuales, tales como el de custodia y vigilancia en el contrato de depósito que por extensión alcanza al de estacionamiento en la "Ley del consumidor".

\section{JURISPRUDENCIA SOBRE DAÑOS REPARABLES}

DENTRO DE UN ESTACIONAMIENTO REGIDO POR LA "LEY SOBRE PROTECCIÓN DE LOS DERECHOS DEL CONSUMIDOR”

Los tribunales chilenos se han pronunciado en varias oportunidades señalando que el contrato de estacionamiento sería un contrato de adhesión, de acuerdo a la definición que la propia Ley No 19.946 ofrece en su artículo 1 No 6 . Este contrato se rige por los artículos 3 letras d) y e), 12 y 23 de la Ley No 19.496. Supletoriamente, a nuestro entender, rigen las normas de los artículos 1915 ss. CC.

Se señala, además, que la convención se perfecciona por el solo hecho de retirarse el "ticket" y pagarse la tarifa de estacionamiento, y desde entonces (2007).

36 "Servicio Nacional del Consumidor con Concesionaria Subterra S.A."

${ }^{37}$ DíEz-Picazo, L., Fundamentos del Derecho civil patrimonial (5a edición, Madrid, Thomson-Civitas, 1996), II, p. 581. Sólo basta en esta línea remitirse a las normas de los artículos correspondientes al contrato de depósito y dentro de él en especial a los artículos 2236 ss. CC. 
el consumidor queda imposibilitado de alterar de manera alguna las cláusulas ofrecidas por el proveedor en el contrato; así por ejemplo en "Servicio Nacional del Consumidor con Saba Park Chile S.A.” del $2006^{38}$.

También se ha fallado que esta actividad tiene el carácter de civil para la persona que consiente en la celebración del contrato de adhesión, así por ejemplo en "González con Vinci Park Chile S.A." (2006), y que es aplicable el artículo 2 de la Ley No $19.496^{39}$.

En este sentido, los tribunales han afirmado que el deber de custodia y guarda del estacionamiento "por su naturaleza y especiales características no puede sino comprender el resguardo de tales vehiculos frente a posibles acciones dañosas de terceros" ${ }^{40}$. Este deber, propio de un depósito, se debe exigir por el acreedor durante todo el contrato, es decir, por todo el lapso que el vehículo está estacionado. El alcance de estos daños es amplísima: daños corporales propios de la persona del depositante del vehículo, daño emergente, lucro cesante y daños extrapatrimoniales o morales. El caso fortuito y la fuerza mayor serían supuestos de exclusión de responsabilidad del deudor frente al incumplimiento.

Los fallos de los tribunales ${ }^{41}$ señalan escuetamente que las normas infringidas serían los artículos 12 y 23 de la Ley No 19.946. Todos destacan que el proveedor de bienes y servicios debe respetar las condiciones que ha ofrecido al consumidor para la prestación de los servicios ${ }^{42}$. El artículo 23, citado también por los fallos, dice relación con los casos de negligencia culpable en la prestación del servicio y consiguiente menoscabo al consumidor.

En otras palabras, ante un daño, la empresa podrá siempre demostrar que ha empleado la debida diligencia o cuidado en el resguardo del vehículo, sus accesorios y efectos que se encuentren en su interior.

En relación a este aspecto las sentencias de nuestros tribunales estiman como inoponibles los informes de seguridad de la empresa que ofrece el estacionamiento y las "investigaciones exhaustivas" que estas mismas

\footnotetext{
38 "Servicio Nacional del Consumidor con Saba Park Chile S.A." (2006), Segundo Juzgado de Policía Local de Santiago, 15 de diciembre de 2006.

39 "González con Vinci Park Chile S.A." (2006), Corte de Apelaciones de Santiago, 16 de junio de 2006. Ley No 19.496, artículo 2: "Quedan sujetos a las disposiciones de esta ley: a) Los actos jurídicos que, de conformidad a lo preceptuado en el Código de Comercio u otras disposiciones legales, tengan el carácter de mercantiles para el proveedor y civiles para el consumidor".

40 "González con Vinci Park Chile S.A." (2006).

41 "Servicio Nacional del Consumidor con Saba Park Chile S.A." (2006); "Jorquera y otro con Blanco y Negro S.A." (2007); y "González con Vinci Park Chile S.A." (2006).

${ }^{42}$ Ley No 19.496, artículo 12.
} 
organizaciones dicen realizar ante el evento de un daño a un vehículo estacionado. Estos “informes" o "investigaciones” prácticamente siempre eximen de responsabilidad a la empresa proveedora del estacionamiento, lo que evidentemente no puede ser considerado seriamente por el tribunal $^{43}$. Asimismo, se ha considerado en tribunales como insuficiente para eximir de responsabilidad a la empresa que ofrece el estacionamiento el ampararse en el dispositivo o procedimientos de seguridad empleados con técnicas de vigilancia por cámaras o circuitos cerrados de televisión. Es más, la mayoría de las veces, además, se ha obligado a la empresa a pagar una multa derivada de la infracción a la "Ley del consumidor", artículo 3 letra e) cuando se ha recurrido a este argumento ${ }^{44}$.

En "Álvaro Jorquera en contra de Blanco y Negro S.A.” no sólo la empresa demandada fue condenada por infracción a la Ley No 19.496, sino que además, el tribunal declaró que había lugar a la responsabilidad civil por el daño patrimonial derivado del robo del automóvil del demandado, fijando el tribunal prudencialmente el daño directo ${ }^{45}$.

La actividad probatoria del demandante, para estos casos, no puede estar basada sólo en la presunción de incumplimiento del artículo 1547 inciso $3^{\circ}$ CC., sino más bien en la prueba de los daños directos e inmediatos, aunque a juzgar por algunas sentencias, ni ello es prenda de éxito de la acción incoada.

Se hace evidente la insuficiencia de nuestra "Ley del consumidor". De la lectura de varios fallos se puede colegir que los jueces de Policía Local rechazan la indemnización de perjuicios a los reclamantes y sí acogen multando al proveedor, como destaca Pizarro ${ }^{46}$.

43 “González con Vinci Park Chile S.A.” (2006) y "Servicio Nacional del Consumidor con Saba Park Chile S.A.” (2006).

${ }^{44} \mathrm{La}$ "Ley del consumidor" permite la persecución de las responsabilidades civiles derivadas de este tipo de situaciones, expresamente en su artículo $3^{\circ}$ letra e) al señalar como derechos del consumidor "[...] la reparación e indemnización adecuada y oportuna de todos los daños materiales y morales en caso de incumplimiento de cualquiera de las obligaciones contraidas por el proveedor, y el deber de accionar de acuerdo a los medios que la ley le franquea".

45 "Jorquera y otro con Blanco y Negro S.A." (2007). El Juzgado de Policía Local de Macul, en primera instancia, determinó que Blanco y Negro cometió infracción a la "Ley del Consumidor" al no respetar lo acordado y no entregar un servicio de calidad, lo que implica en este caso, el resguardo del vehículo, tesis que llevó a la Corte de Apelaciones a ratificar el fallo.

${ }^{46}$ Pizarro Wilson, C. El fracaso de un sistema: Análisis empirico y dogmático del control de cláusulas abusivas en contratos por adhesión, en Revista de Derecho, 20 (Valdivia, 2007) 2, pp. 31-47. [versión electrónica:http://www.scielo.cl/scielo. php?script=sci_arttext\&pid=S071809502007000200002\&lng=es\&nrm=iso 
Al dueño del establecimiento no le es permitido eximirse, mediante cláusulas unilaterales predispuestas, de las secuelas nacidas de su propia negligencia y que terminan perjudicando al consumidor ${ }^{47}$. A mayor abundamiento, el artículo 4 de la Ley No 19.496, establece que los derechos consagrados en este estatuto, son irrenunciables anticipadamente por el usuario y así lo han entendido los tribunales en correspondencia con el artículo 16 letra e) del mismo cuerpo de normas ${ }^{48}$. En esta línea, la hoja de reclamaciones debidamente cumplimentada ante un daño ocurrido, ya en un juicio, se ha tornado importante en la valoración de la prueba por daños como pérdida o robo de objetos.

En cuanto a qué daños comprende una eventual indemnización por pérdida o sustracción que sufra el vehículo, los tribunales se ciñen a lo que obra en la prueba presentada. Se ha sostenido en estrados que la reparación debe extenderse no sólo al vehículo y a sus accesorios funcionales, ruedas, antenas, vidrios, focos, espejos, radio del vehículo, sino que también a cualquier objeto de carácter mueble que se encuentre al interior del mismo y bajo la esfera de cuidado del dueño de los estacionamientos, no fuera de él, tal y como quedó claro en un fallo de la Corte de Apelaciones de

${ }^{47}$ Ley No 19.496, artículo 16: "No producirán efecto alguno en los contratos de adhesión las cláusulas o estipulaciones que:/ c) Pongan de cargo del consumidor los efectos de deficiencias, omisiones o errores administrativos, cuando ellos no le sean imputables;/ d) Inviertan la carga de la prueba en perjuicio del consumidor;/ e) Contengan limitaciones absolutas de responsabilidad frente al consumidor que puedan privar a éste de su derecho a resarcimiento frente a deficiencias que afecten la utilidad ofinalidad esencial del producto o servicio".

${ }^{48}$ Señala un fallo de la Corte de Apelaciones de Santiago, de 2007: "De conformidad al artículo 16 letra e) de la Ley No 19.496, las cláusulas que contengan limitaciones absolutas de responsabilidad frente al consumidor que puedan privar a éste de su derecho a resarcimiento frente a deficiencias que afecten la utilidad o finalidad esencial del producto o servicio, carecen de todo valor y, consecuentemente, los anuncios de la concesionaria de un servicio de estacionamiento en orden a que no se hace responsable por los hurtos, robos o accidentes que ocurran al interior del mismo, no produce efecto alguno respecto del usuario del servicio. El concesionario de un servicio responde de culpa leve, de modo que al momento de contratar con una persona cualquiera, el acreedor espera el comportamiento que ordinariamente el deudor despliega en la gestión de sus negocios. Esto implica que la ley, por lo general, no formula una exigencia desmedida, pero tampoco permite una degradación de la diligencia que habitualmente emplea una persona en su vida de relación. Incurre en falta de cuidado constitutivo de culpa leve, el servicio deficiente de la concesionaria explicado en la ausencia de elementos humanos o de infraestructura que permitan mantener bajo control las condiciones del recinto del estacionamiento, configurando la infracción contemplada en el articulo 23 inciso primero de la Ley No 19.496." No se consigna parte con Concesionaria Subterra S.A. Corte de Apelaciones de Santiago (2007). 
Santiago, de 2008: "Si bien el establecimiento comercial presta un servicio de estacionamiento a sus clientes, el cual forma parte del mismo y le obliga en cualquier circunstancia a que debe adoptar las medidas necesarias de resguardo y seguridad, como en todos los servicios que ofrece, no es posible imputársele una acción negligente respecto de un vehículo estacionado en un lugar que la empresa no ha habilitado para tal efecto. En estas condiciones, la sustracción del vehiculo del denunciante y demandante civil desde una calle lateral y en zona probibida, que no pertenecía a los estacionamientos del establecimiento, no configura una infracción al artículo 23 de la Ley No 19.496, porque el prestador no se encontraba obligado a adoptar medidas de seguridad a su respecto" 49 .

En otro fallo de la Corte de Apelaciones de Santiago, de 2007, se señala: "como también lo reconoce la denunciada, el servicio que presta a los usuarios es mantener sus vehiculos en los estacionamientos en condiciones seguras, por lo que corresponde determinar si en el presente caso efectivamente cumplió con lo contratado. Como no se discutió el hecho de la sustracción, resulta evidente que el servicio ofrecido fue deficiente, sin que sea admisible como excusa el que la especie sustraida era desmontable o que debió quedar en las cajas de seguridad. De aceptarse estas explicaciones, ello importaría hacer de cargo del usuario la seguridad que la empresa está obligada a proporcionar en toda circunstancia y por la que cobra un precio que fija unilateralmente" 50 .

Los tribunales han señalado, en general, que se debe restituir a los propietarios cuyos vehículos han sufrido daños en los componentes y accesorios que sean fijos e inseparables y los que comúnmente están dentro de los vehículos. No estarían dentro de este género, los extraíbles tales como celulares, radios desmontables, "notebook", entre otros, los que deben ser probados en su existencia al interior del vehículo por los consumidores. Como solución a la eventual pérdida de los periféricos o accesorios dejados al interior de un automóvil, siempre existe la posibilidad de que las empresas ofrezcan un servicio adicional de custodia, verdadero contrato de depósito accesorio, para resguardar estos bienes muebles que no escaparía de esa forma en lo absoluto al deber de custodia y vigilancia de esta modalidad como se ve en los fallos estudiados.

En lo relativo al deber de diligencia, y pese a que creemos que debiera ser más elevado, es la culpa leve como deber de cuidado el que les ha sido impuesta por los tribunales a los proveedores y consumidores en los casos planteados por daños producidos al interior de estacionamiento. Creemos

49 "Carlos David Ávila Jiménez, Servicio Nacional del Consumidor con "A and V Mercado de Conveniencia S.A.” (considerando 4\%).

50 "Estacionamientos Santa Lucía con Hernández Heredia, Juan", Corte de Apelaciones de Santiago (2007). 
que es el criterio correcto en principio, pero sin embargo debiera tenderse a un estándar más alto propio de una organización como ya explicamos. Quien explota un estacionamiento lo hace en el marco de una organización o aprovechamiento de carácter mercantil, lo que ha de llevar a aumentar las medidas de diligencia ordinarias en la precaución de eventuales daños a los consumidores. Esto no es cualquier índice o nivel de diligencia, sino aquel que se relaciona con el lugar, tiempo y las personas involucradas. Recordemos que nuestra argumentación se sustenta en una razón histórica, pues los casos de custodia en la responsabilidad civil son prácticamente objetivas al estar basadas en actos positivos del deudor o en violaciones de deberes contractuales, tales como el de custodia y vigilancia en el contrato de depósito, que por extensión, alcanzan al del contrato de estacionamiento regido por la "Ley del consumidor" 51 .

No se piense que sólo tienen deberes los proveedores del estacionamiento, pues ambas partes han de cumplir con sus obligaciones como en cualquier contrato bilateral. Así, el que estaciona su automóvil no debe exponerse imprudentemente al riesgo dejando, por ejemplo, el automóvil abierto, sin su alarma o con los vidrios abajo. De no cumplirse por parte del usuario estos criterios, que por lo demás responden a lo razonable, se puede aminorar la responsabilidad imputable al proveedor del servicio.

\section{JURISPRUDENCIA SOBRE RESPONSABILIDAD EN EL CASO DE DAÑOS, HURTOS O ROBOS EN ESTACIONAMIENTOS GRATUITOS}

Puede acaecer que el estacionamiento ofrecido por una empresa sea gratuito y que el potencial cliente ingrese en él y no compre en aquélla. $\mathrm{O}$ que alguien ocupe el estacionamiento gratuito de cierta empresa sin consumir en el local de ésta sino en el de otra. Lo primero que cabe precisar aquí es que ésta es una situación anormal, que no será la regla general, pero que ocurre.

Esto puede representar un problema, porque como el artículo 2 de la "Ley del consumidor" cometió el error de definir los actos de comercio, y señaló que quedan sujetos a sus disposiciones: “a) los actos jurídicos que, de conformidad a lo preceptuado en el Código de Comercio u otras disposiciones legales, tengan el carácter de mercantiles para el proveedor y civiles para el consumidor". No pocas veces, a la luz de este precepto, se ha presentado en estrados la alegación de que no celebra acto de comercio quien ingresa

${ }^{51}$ Díez-Picazo, L., Fundamentos, cit. (n. 37), p. 581. Sólo basta en esta línea remitirse a las normas de los artículos correspondientes al contrato de depósito y dentro de él en especial a los artículos 2236 ss. CC. referidos al contrato de depósito. 
a un estacionamiento gratuito de una multitienda y se retira sin consumir de ella ${ }^{52}$.

Todo hace suponer que si alguien usa el estacionamiento de un supermercado, por ejemplo, lo hace a cambio de la función del tiempo real de prestación del servicio. Ahora bien, este usuario en realidad es igualmente un consumidor de acuerdo a la solución adoptada en nuestra jurisprudencia porque la normativa no distingue entre consumidores en sentido estricto y amplio. Son todos consumidores, terminen o no la relación de consumo. Así lo ha fallado la jurisprudencia chilena reciente: "De tal modo no es posible concluir que el servicio de estacionamiento gratuito constituya un servicio anexo, adicional o diferente de la mera venta de mercancías o servicios, sino que forma parte de la oferta de la denunciada, quien no ha dado cumplimiento a su obligación de resguardar la seguridad en el consumo de los bienes, y en particular en el resguardo de bienes de su cliente. En efecto, para tales efectos la denunciada cuenta, tal como consta de los antecedentes de un servicio de resguardo, cuyo fin radica esencialmente en otorgar un minimo de seguridad en la realización y operación del acto especifico de la prestación de servicios de venta de mercancías o servicios" 53 .

No se hace diferencia en la actualidad, en doctrina comparada, entre

${ }^{52}$ Desafortunadamente, desde este punto de vista, la delimitación de actos de comercio que hizo el legislador en el artículo segundo de la Ley No 19.496. Tal y como señala Carvajal Ramírez, Patricio Ignacio, Sugerencias para un derecho de consumo unitario, en Revista Chilena de Derecho, 29 (2002) 1, p. 136: "La distinción sobre base subjetiva sólo es útil desde un plano didáctico, de racionalización del problema. 'Contrato de consumidores', 'contrato de empresa', 'contrato de particulares' no pasan de ser categorías descriptivas, pues la causa y el tipo de contrato es lo relevante para su calificación dentro del ámbito de la autonomía privada. Debe resultarnos aleccionador el hecho que ya hace tiempo la doctrina mercantilista, ante la heterogeneidad que presentaban los códigos, renunció a buscar por el método inductivo un 'acto de comercio' [...]".

${ }^{53}$ Este caso fue conocido por la Corte de Apelaciones de Santiago, que condenó a la empresa Hipermercado Alameda Ltda. a cancelar una multa de 25 UTM, y al pago de una indemnización de $\$ 1.384 .900$ por daño moral y daño emergente a Nancy Gabelo Ocampo, cuyo auto fue robado en el estacionamiento del Hipermercado señalado. En fallo unánime, los ministros de la Sexta Sala Juan Eduardo Fuentes, Joaquín Billard y el abogado integrante Nelson Pozo, acogieron la demanda de Nancy Gabelo Ocampo. El fallo establece que los estacionamientos son partes integrantes del servicio prestado, por lo tanto, la empresa es responsable por los daños que sufran los vehículos que son estacionados en él, ello mientras los consumidores se desplazan al interior del supermercado. El fallo es de cinco de enero de dos mil nueve y el recurso es el 9663/2008, Resolución: 1497. Esta sentencia tuvo amplia difusión en los medios de comunicación social, vid. http://www.emol.com/noticias/nacional/ detalle/detallenoticias.asp?idnoticia $=338531$ 
los estacionamientos gratuitos y los pagados, incluso en la jurisprudencia chilena ya se leen fallos en que se señala que: "Dentro del acto jurídico del artículo $2^{\circ}$ letra a) de la Ley $N^{\circ} 19.496$ que las grandes tiendas, conjuntos comerciales y supermercados dirigen al público, se comprende la oferta de estacionamientos y demás servicios complementarios e inseparables del giro, de manera que las fallas o deficiencias en la calidad o seguridad, entre otros, de estos servicios anexos propios del acto de consumo, tal como la sustracción de un vehiculo estacionado en un supermercado, producido mientras la persona que lo dejó en dicho lugar compraba en el establecimiento comercial, pueden constituir una infracción a la Ley $N^{o} 19.496$ en la medida que, por un lado, se deban o sean atribuibles a negligencia del proveedor y, por otro, el consumidor acredite la existencia del acto jurídico base, oneroso, producido entre éste y el proveedor, correspondiendo su conocimiento a los juzgados de policía local (considerandos $9^{\circ}, 10^{\circ}, 11^{\circ}, 12^{\circ}$ y $13^{\circ}$ ). "En efecto, los grandes establecimientos comerciales tienen la obligación legal de contar con estacionamientos y otros servicios complementarios al giro, los cuales pasan a ser un factor comercial esencial para que el público concurra a ellos y forman parte integrante e inseparable del acto jurídico de venta entre proveedor y consumidor, por cuanto la transacción jurídica no podría realizarse sin ellos, situación que se comprueba por la circunstancia que el proveedor adopte medidas de seguridad que persiguen evitar daños a la persona y bienes de los consumidores, que puedan ocurrir en sus recintos" (considerandos $7^{\circ}$ y $\left.8^{\circ}\right)^{54}$

A los dueños de estos estacionamientos de carácter gratuito les cabe tanta responsabilidad como a los de aquellos en que se paga precio o tarifa, en aplicación de los artículos 3, 12 y 23 de la Ley No 19.496.55

De esta forma, y aún en casos de gratuidad de estacionamientos, según señala un fallo de la Corte de Apelaciones de Santiago de 2007: "Se da el presupuesto legal, previsto en el artículo 23 de la ley 19.496, y por tanto cabe responsabilizar al supermercado por la sustracción de un automotor estacionado por un consumidor que concurrió a adquirir productos en el establecimiento, ya que en su elección privilegia al establecimiento que por contar con cámaras de circuito cerrado y guardias, le ofrece seguridad que al estacionar un móvil tendrá la adecuada protección y, al no ser asi, ha existido de parte del proveedor una deficiencia en la prestación del servicio" ${ }^{56}$.

54 "Erika Verónica Sandoval Lecaros, Servicio Nacional del Consumidor con Supermercado Santa Rosa Limitada”, Corte de Apelaciones de San Miguel (2008).

${ }^{55}$ No siempre fue así; se entiende por algunos tribunales que es imposible el control en estos estacionamientos; así en "Gómez Escobar, Christián con Supermercado Jumbo", rol No 126.039-5-2004, Segundo Juzgado de Policía Local de Las Condes.

56 "Vergara Barrera, Erwin J. con Marín, Juan P.” (2007). 
Los estacionamientos gratuitos no lo son realmente, y constituyen parte del servicio que entrega la empresa. El principal objetivo de un estacionamiento gratuito es atraer clientes y con ello que estos adquieran finalmente los bienes y servicios que se ofrecen. Se puede o no realizar la compra, pero la oferta y el acto de consumo ya se iniciaron y con ello los deberes contractuales correspondientes. El estacionamiento gratuito es parte del servicio final y así se entendió en "Romero con Cencosud Supermercados S.A.", de $2005^{57}$.

En una sentencia pronunciada por la Sexta Sala de la Corte de Apelaciones de Santiago de este año 2009 "Gabelo con Hipermercado Alameda"58, se estima como imposible pensar que si finalmente no se compra nada, no estuviese el consumidor bajo el supuesto que la ley exige para entender perfeccionada la llamada "relación de consumo".

Si el consumidor ingresa o no en un recinto del supermercado, pintado con los colores del supermercado y en el que, además, se señala que pertenece a los clientes del establecimiento, lo que hace el oferente o proveedor es brindar comodidad y posibilidad de acceso que permite al consumidor dejar su vehículo en el lugar para comprar. Esta oferta de gratuidad es un aliciente para concurrir a un determinado lugar por sobre otros que ofrezcan estacionamientos pero pagados ${ }^{59}$.

Es más, estimamos que esta misma regla ha de darse para aquellos estacionamientos que ofrecen fracciones de tiempo gratis y que luego de cierto lapso comienzan a cobrar. En estos casos el servicio de estacionamiento se presta como contraprestación a las compras realizadas o que se realizarán eventualmente, mal podemos afirmar que quien no realiza la compra no sea un consumidor que ya ha iniciado una relación de consumo. Tiene sentido lo anterior porque: "la ausencia de precio no responde a un ánimo de liberalidad, pues la existencia del estacionamiento reporta un beneficio indirecto a la instalación o establecimiento a cuyo servicio se encuentra aquél, actuando como reclamo y produciendo por tanto un incremento en su volumen de negocio" 60 .

Lo visto confirma que este servicio de estacionamiento es también una actividad del proveedor del servicio principal, que está dirigida a un lucro, así se falló en "González con Vinci Park Chile S.A.", de 2006"

57 "Romero con Cencosud Supermercados S.A." (2005).

58 "Gabelo con Hipermercado Alameda Limitada" (2009).

59 “Astudillo con Supermercado El Líder" (2006).

${ }^{60}$ Seisdedos, Ana, Ámbito de aplicación de la ley 40/2002, reguladora del contrato de aparcamiento de vehículos, después de su reforma en 2006, en Revista de Derecho Privado (mayo-junio 2007), pp.19-20.

61 "González con Vinci Park Chile S.A." (2006). 
que no puede pretender escindirse de ella el proveedor en orden a intentar configurar algún tipo de exención de responsabilidad.

La Corte de Apelaciones de San Miguel en un fallo de 2008 ha señalado que es evidente que la oferta de estos estacionamientos gratuitos en las dependencias del Supermercado, no son respuesta a una mera liberalidad o concesión graciosa, sino que responden a regulaciones propias de la "Ley de urbanismo", sin las cuales no habrían recibido autorización municipal para edificar y desarrollar la actividad comercial de su giro ${ }^{62}$. De aquí se desprende que, incluso en el caso de un estacionamiento gratuito, lo que se desarrolla es una actividad comercial, pese a que no se pague por estacionarse en él ${ }^{63}$.

Sin embargo, a nivel de juzgados de policía local no parece compartirse con el mismo énfasis el criterio de la Corte de Apelaciones de San Miguel, pues en un fallo de 2007 recaído en "Loayza con Supermercado Jumbo" se señala que los estacionamientos del supermercado, al ser de libre acceso, carecerían de control alguno, tanto a su entrada como salida. Esta situación, lleva a concluir a la sentenciadora que cualquier persona puede acceder a los estacionamientos, lo que es imposible de controlar (incluido eventuales ladrones, como parecía era el caso). Esto excluye para el tribunal la relación de consumo per se. Un estacionamiento gratuito de estas características no permite considerar como dentro del giro de supermercados el prestar servicios de estacionamientos. Tampoco se pudo en el caso sometido a estudio determinar si se ocupó o no por parte del cliente del supermercado la plaza de estacionamiento ${ }^{64}$.

Una de las formas de defensa de los supermercados por daños en los estacionamientos públicos, gratuitos o no, es alegar la excepción del No 6 del artículo 303 CPC.: "En general las que se refieran a la corrección del procedimiento sin afectar al fondo de la acción deducida". Se fundan para ello estos proveedores en que la acción deducida se ha dirigido erróneamente en contra del supermercado, quien no es ni ha sido nunca dueño de los estacionamientos. Los tribunales han desestimado tal alegación, básicamen-

62 "Servicio Nacional del Consumidor con Supermercado Santa Rosa Limitada" (2008).

${ }^{63}$ Sobre este punto resultan interesantes las reflexiones en el comentario de sentencia de VAras, J. A., Sentencia sobre la naturaleza jurídica del aparcamiento dispuesto por una casa comercial (Segundo Juzgado de Letras de Valdivia) en Revista de Derecho de la Universidad Austral de Valdivia, 16 (julio de 2004), pp. 241-247.

64 "Loayza con Supermercado Jumbo", rol No 18.950-5-2007, Segundo Juzgado de Policía Local de Las Condes. Este era, según la relación de los hechos, un caso de robo con fuerza de un vehículo, en los estacionamientos interiores del supermercado Jumbo Bilbao en Santiago. 
te porque entienden que, si bien, puede ser que los estacionamientos no pertenezcan a la empresa dueña del supermercado, el lugar se identifica por señales como propio o disponible para los clientes del supermercado.

A nuestro juicio, el consumidor no puede saber que los estacionamientos han sido arrendados a otra empresa. Es más, es un estacionamiento gratuito o remunerado de los clientes de ese supermercado según las señales habituales y, en todo caso, "ante la apariencia de las cosas el consumidor no puede saber o conocer la intermediación existente." En definitiva, deberá considerarse en estos casos que aun cuando la demandada hubiere alegado un contrato de arrendamiento que hubiese hecho responsable de los daños a la empresa que arrienda al supermercado los estacionamientos, "resulta aplicable el artículo 43 de la ley 19.496, que señala: 'El proveedor que actúe como intermediario en la prestación de un servicio responderá directamente frente al consumidor por el incumplimiento de las obligaciones contractuales, sin perjuicio de su derecho de repetir contra el prestador de los servicios o terceros que resulten responsables" 65 .

Lo dicho en relación a los supermercados también se ha aplicado en el caso de los hoteles. En efecto, en "Sernac con Hotel Marriot", de 2004, se señalaba que pese a que en las mismas instalaciones, además del hotel, coexistan otras entidades dedicadas a sus propias actividades, un cliente del hotel tiene igualmente el privilegio de gozar de un estacionamiento en forma gratuita, lo que además puede acreditar mediante el ticket de estacionamiento timbrado por el hotel ${ }^{66}$. Si ello es así, para la sentenciadora, "deberán necesariamente considerarse el estacionamiento que ocupa un cliente del Hotel Marriott como parte integrante del servicio que presta". Esto, además es así a juicio del tribunal, porque ante la apariencia de las cosas, el consumidor no puede saber o conocer la intermediación existente en el servicio que se le presta.

\section{CONCLUSIONES}

a) No es una sola la reglamentación que puede regir al contrato de estacionamiento; sin embargo de lo cual nos parecen claros los criterios que relacionan este contrato al de depósito y al de arrendamiento civiles cuando no les es aplicable la Ley No 19.496.

b) Los tribunales chilenos se han pronunciado en varias oportunidades señalando que el contrato de estacionamiento sería un contrato de adhe-

65 "Gómez Escobar, Christián con Supermercado Jumbo", rol No 126.039-52004, Segundo Juzgado de Policía Local de Las Condes.

66 "Sernac con Hotel Marriot", rol No 128.811-5-2004, Segundo Juzgado de Policía Local de Las Condes. 
sión, de acuerdo con la definición que la propia Ley No 19.946 ofrece en su artículo 1 No 6 . Este contrato se regiría por los artículos 3 letras d) y e), 12 y 23 de la Ley No 19.496. Supletoriamente, a nuestro entender, rigen los artículos 1915 ss. y 2211 CC.

c) Dentro del Derecho del consumidor, y en el ámbito de aplicación de la Ley No 19.496, se espera de los proveedores de servicios de estacionamiento, gratuitos o remunerados, una función de garantía y seguridad para con el consumidor, no sólo en su persona sino que también en sus bienes. Ello, de acuerdo a la jurisprudencia analizada, con independencia de si el consumidor compra o no el bien ofertado porque el deber de seguridad va implícito en la oferta misma del proveedor. Todo parece indicar que la posición de garante del oferente del estacionamiento es fundamental, tenga esta un origen contractual o legal.

d) Somos partidarios de elevar el grado de diligencia del proveedor de estacionamientos a uno especialmente cualificado. Este nivel se caracteriza como aquel que se impone a los profesionales o empresarios en una actuación económica. Lo anterior porque creemos que quien explota un estacionamiento lo hace en el marco de una organización o explotación de carácter mercantil que ha de aumentar las medidas de diligencia ordinarias en la precaución de eventuales daños a sus consumidores.

[Recibido el 7 de septiembre de 2009 y aprobado el 15 de mayo de 2010].

\section{BibLIOGRAFÍA}

Álvarez Pérez, N., El contrato de aparcamiento de vehículos. Notas a la Ley 40/2002, de 14 de noviembre, en In Dret, 2 (2003).

Arroyo Aparicio, Alicia, El contrato de aparcamientos de vehículos (Madrid, Marcial Pons, 2008).

Ballesteros de los Ríos, M., El contrato de aparcamiento (Pamplona, Aranzadi, 2000). .

Barrientos Zamorano, M., Daños y deberes en las tratativas preliminares de un contrato, (Santiago, LegalPublishing, 2008).

Barros Bourie, E., Tratado de responsabilidad extracontractual (Santiago, Editorial Jurídica de Chile, 2006).

Bercovitz Rodríguez-Cano, R., Aparcamientos, en Aranzadi Civil, 15 (noviembre de 2002).

Bourgoignie, Thierry, Elementos para una teoria del Derecho de consumo (Vitoria, Departamento de Comercio, Consumo y Turismo de la Comunidad Vasca, 1994).

Carrasco Perera, A. - Medoza losana, A. I., El carácter abusivo de la fórmula "hora o fracción" en los contratos de aparcamiento, en La Ley, 5588 (16 de julio de 2002). 
Carvajal Ramírez, Patricio Ignacio, Sugerencias para un derecho de consumo unitario, en Revista Chilena de Derecho, 29 (2002) 1.

Cazorla González, M. J., La responsabilidad derivada del contrato de aparcamiento, en Actualidad Civil, 6 (7 al 13 de febrero de 2000).

Corral Talciani, H., Lecciones de responsabilidad civil extracontractual (Santiago, Editorial Jurídica de Chile, 2003).

Díez Soto, C. M., El depósito profesional (Barcelona, Bosch, 1995).

Díez-Picazo, L. Fundamentos del Derecho civil patrimonial (5a edición, Madrid, Thomson-Civitas, 1996).

Elguero y Merino, J. Ma , Garajes y aparcamientos: ¿arrendamiento o depósito?, (Madrid, Tecnos, 1993).

Gallego Domínguez, Ignacio, Comentarios a la ley reguladora del contrato de aparcamiento de vehículos, ley 40/2002, de 14 de noviembre. (Granada, Comares, 2003).

Gómez Calle, E., Los deberes precontractuales de información, en La Ley (1994).

Herrada Romero, R. I., El contrato de garaje, (Madrid, Edersa, 2000).

Herrada, Rafael Ignacio, El contrato de garaje y la ley 40/2002, reguladora del contrato de aparcamiento de vehículos, en Revista de Derecho Privado (enero-febrero de 2004).

Huet, J., Traité de Droit civil (sous la direction de Jacques Ghestin). Les principaux contrats spéciaux (Paris, L.D.G.J., 1996).

Morales Moreno, A. M., El error en los contratos (Madrid, Ceura, 1988).

Núñez Cabrera, D., Declaraciones y silencios en el ámbito precontractual, en Estudios de Derecho Civil (Santiago, LexisNexis, 2007), II.

PiZARRo WiLson, C. La culpa como elemento constitutivo del incumplimiento en las obligaciones de medio o de diligencia, en Revista de Derecho de la Pontificia Universidad Católica de Valparaíso, 30 (2008) 2.

Pizarro Wilson, C., El fracaso de un sistema: Análisis empírico y dogmático del control de cláusulas abusivas en contratos por adhesión, en Revista de Derecho de la Universidad Austral, 20 (Valdivia, 2007) 2.

RePresa Polo, P., Responsabilidad de los establecimientos hoteleros por los efectos introducidos por sus clientes, (Madrid, Editoriales de Derecho Reunidas, 2004).

SeISDEDos, Ana, Ámbito de aplicación de la ley 40/2002, reguladora del contrato de aparcamiento de vehiculos, después de su reforma en 2006, en Revista de Derecho Privado (mayo-junio de 2007).

Tapia Rodríguez, M. - Valdivia, J. M., Contrato por adhesión. Ley No 19.496 (Santiago, Editorial Jurídica de Chile, 2002).

Tapia Rodríguez, M., Código Civil, 1855-2005, evolución y perspectivas (Santiago, Editorial jurídica de Chile, 2005).

Vaquero Pinto, M. J., Los contratos de estacionamiento de vehículos (algunas reflexiones a propósito de la sentencia del Tribunal Supremo de 22 de octubre de 1996), en Estudios sobre Consumo, 48 (1999).

VARAS, J. A., Sentencia sobre la naturaleza juridica del aparcamiento dispuesto por una casa comercial (Segundo Juzgado de Letras de Valdivia), en Revista de Derecho de la Universidad Austral, 16 (Valdivia, julio de 2004). 
